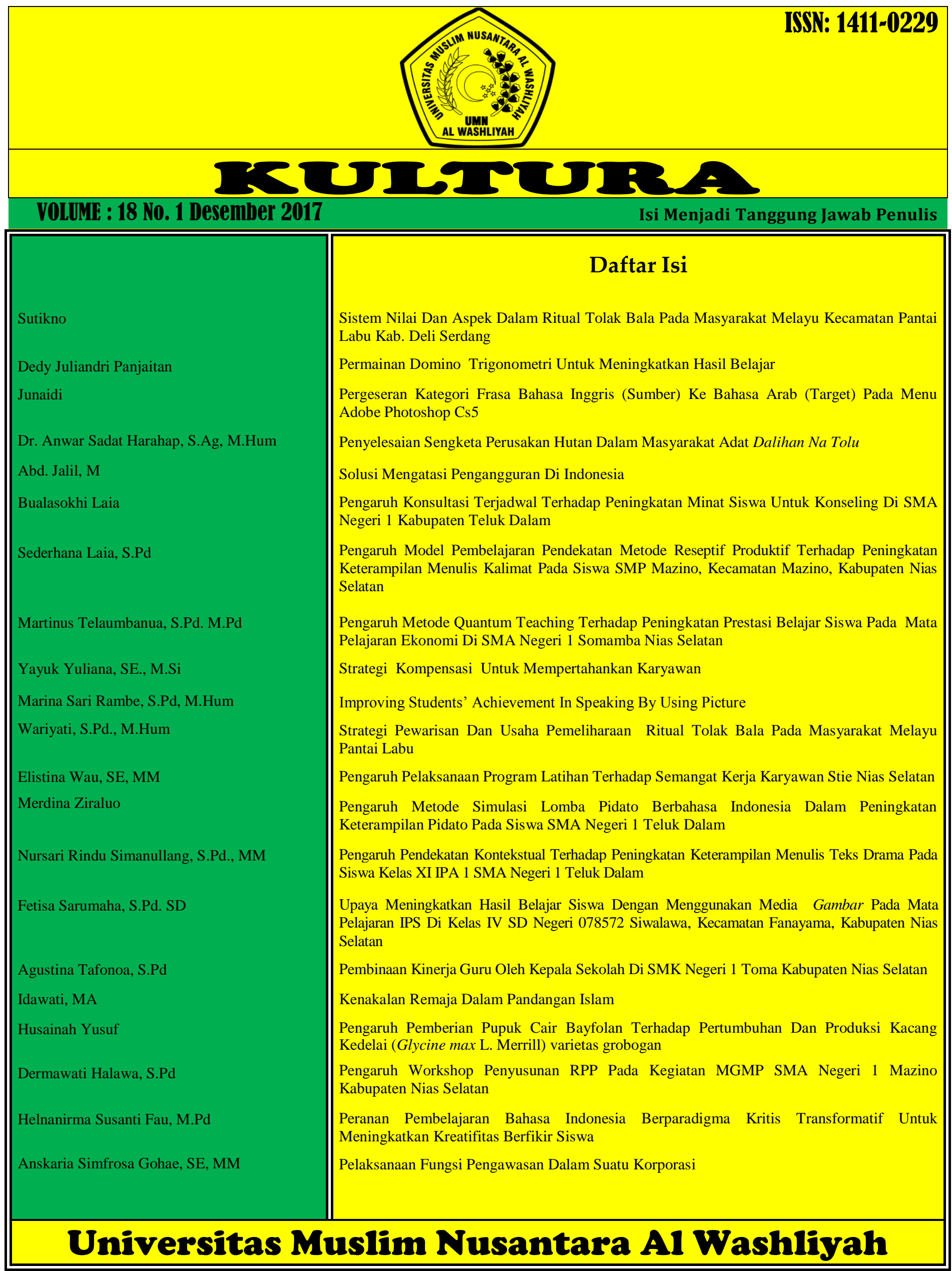




\section{JURNAL ILMIAH

\section{VOL. 18 NO. 1 MARET 2017}

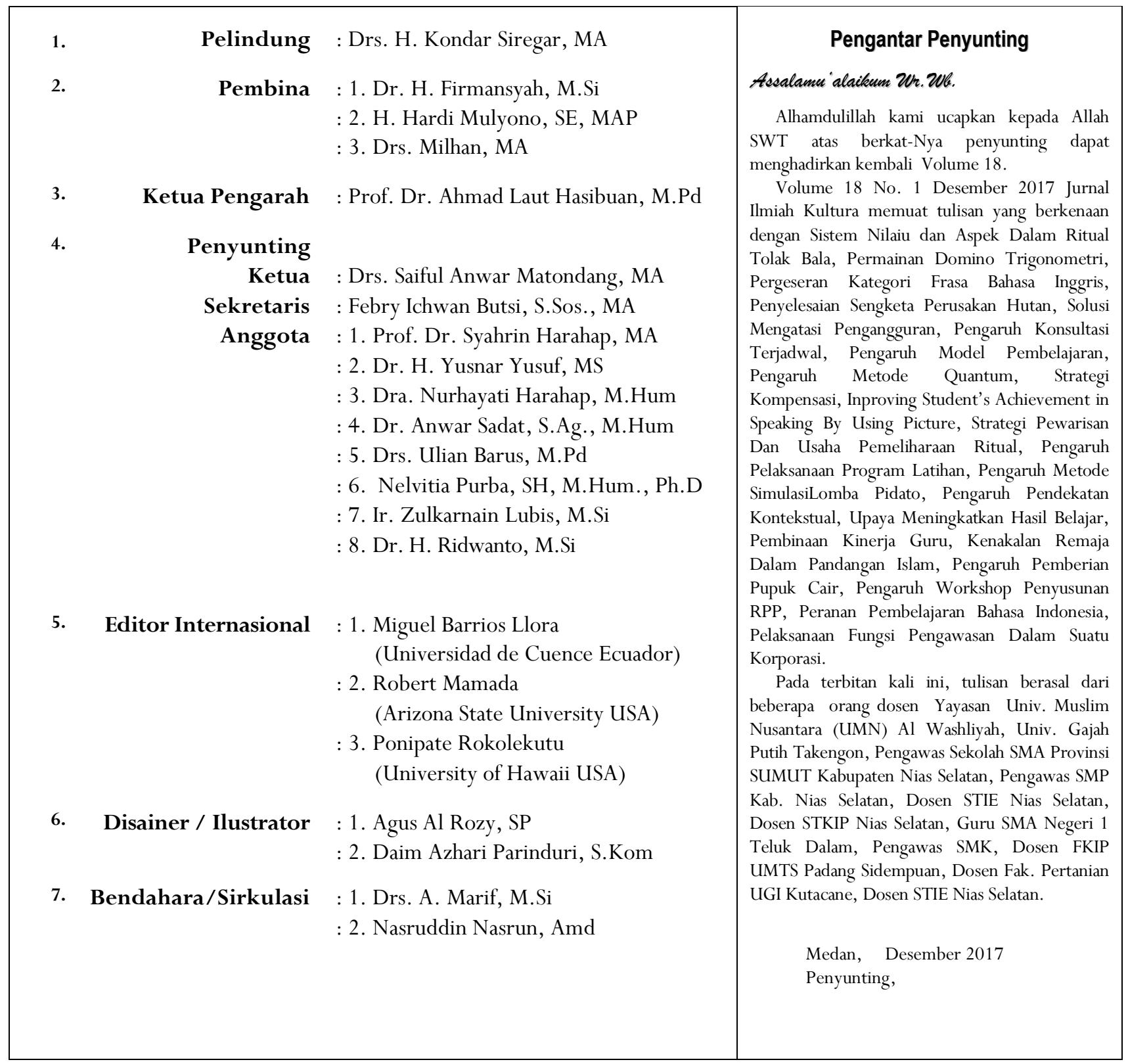

\section{Penerbit:}

\section{Universitas Muslim Nusantara (UMN) Al Washliyah Alamat Penerbit / Redalesi:}

J1. Sisingamangaraja/Garu II No. 93 Medan 20147

Telp. (061) 7867044 - 7868487 Fax. 7862747

Home Page: http://www.umnaw.ac.id/?page_id-2567

E-mail: info@umnaw.ac.id

Terbit Pertama Kali : Juni 1999

JURNAL TRIWULAN 


\section{Vol. 18 No. 1 Desember 2017}

\section{DAFTAR ISI}

Sistem Nilai Dan Aspek Dalam Ritual Tolak Bala Pada Masyarakat Melayu Kecamatan Pantai Labu Kab. Deli Serdang

(Sutikno).

Permainan Domino Trigonometri Untuk Meningkatkan Hasil Belajar

(Dedy Juliandri Panjaitan)

Pergeseran Kategori Frasa Bahasa Inggris (Sumber) Ke Bahasa Arab (Target) Pada Menu Adobe Photoshop Cs5

(Junaidi)

Penyelesaian Sengketa Perusakan Hutan Dalam Masyarakat Adat Dalihan Na Tolu

(Dr. Anwar Sadat Harahap, S.Ag, M.Hum)

Solusi Mengatasi Pengangguran Di Indonesia

(Abd. Jalil, M)

Pengaruh Konsultasi Terjadwal Terhadap Peningkatan Minat Siswa Untuk Konseling Di SMA Negeri I Kabupaten Teluk Dalam

(Bualasokhi Laia)

Pengaruh Model Pembelajaran Pendekatan Metode Reseptif Produktif Terhadap Peningkatan Keterampilan Menulis Kalimat Pada Siswa SMP Mazino, Kecamatan Mazino, Kabupaten Nias Selatan

(Sederhana Laia, S.Pd)

Pengaruh Metode Quantum Teaching Terhadap Peningkatan Prestasi Belajar Siswa Pada Mata Pelajaran Ekonomi Di SMA Negeri I Somamba Nias Selatan

(Martinus Telaumbanua, S.Pd. M.Pd)

Strategi Kompensasi Untuk Mempertahankan Karyawan

(Yayuk Yuliana, SE., M.Si)

Improving Students' Achievement In Speaking By Using Picture

(Marina Sari Rambe, S.Pd, M.Hum)

Strategi Pewarisan Dan Usaha Pemeliharaan Ritual Tolak Bala Pada Masyarakat Melayu Pantai Labu

(Wariyati, S.Pd., M.Hum)

Pengaruh Pelaksanaan Program Latihan Terhadap Semangat Kerja Karyawan Stie Nias Selatan

(Elistina Wau, SE, MM)

Pengaruh Metode Simulasi Lomba Pidato Berbahasa Indonesia Dalam Peningkatan Keterampilan Pidato Pada Siswa SMA Negeri 1 Teluk Dalam

(Merdina Ziraluo)

Pengaruh Pendekatan Kontekstual Terhadap Peningkatan Keterampilan Menulis Teks Drama Pada Siswa Kelas XI IPA 1 SMA Negeri 1 Teluk Dalam

(Nursari Rindu Simanullang, S.Pd., MM)

Upaya Meningkatkan Hasil Belajar Siswa Dengan Menggunakan Media Gambar Pada Mata Pelajaran IPS Di Kelas IV SD Negeri 078572 Siwalawa, Kecamatan Fanayama, Kabupaten Nias Selatan Tahun Pelajaran 2016/2017

(Fetisa Sarumaha, S.Pd.SD)

Pembinaan Kinerja Guru Oleh Kepala Sekolah Di SMK Negeri 1 Toma Kabupaten Nias Selatan

(Agustina Tafonoa, S.Pd)

Kenakalan Remaja Dalam Pandangan Islam

(Idawati, MA)

Pengaruh Pemberian Pupuk Cair Bayfolan Terhadap Pertumbuhan Dan Produksi Kacang Kedelai (Glycine max L. Merrill) Varietas Grobogan

(Husainah Yusuf)

6989

Pengaruh Workshop Penyusunan RPP Pada Kegiatan MGMP SMA Negeri 1 Mazino Kabupaten Nias Selatan

(Dermawati Halawa, S.Pd)

Peranan Pembelajaran Bahasa Indonesia Berparadigma Kritis Transformatif Untuk Meningkatkan Kreatifitas Berfikir Siswa (Helnanirma Susanti Fau, M.Pd)

Pelaksanaan Fungsi Pengawasan Dalam Suatu Korporasi

(Anskaria Simfrosa Gohae, SE, MM) 


\title{
PERGESERAN KATEGORI FRASA BAHASA INGGRIS (SUMBER) KE BAHASA ARAB (TARGET) PADA MENU ADOBE PHOTOSHOP CS5
}

\begin{abstract}
Junaidi ${ }^{1}$
ABSTRAK

This research describes about the shift of Phrase Categories of menus in Adobe Photoshop CS5, a graphic design program developed by Adobe Corporation. The theory which is used to analyze is shift category and syntactical construction by generative transformation. The Shift category applied in the research is Catford (1965), The sytanctical step of the research applied in the research is Burton-Robert theory (1984) Descriptive qualitative by adopting Miles and Huberman method (1984 and 1992) is also implemented in data analysis particularly. The data of this research are the menus which occur in English version and Arabic version of Adobe Photoshop CS5 that was restricted at menu file's section which totalized around 1254 menus. As for the result of the research indicated that there are four shifted constructions of phrase from english into Arabic; 1 . Shifted Noun Phrase (English) to be Adjective Phrase (Arabic), 2. Shifted Noun Phrase (English) to be Prepotition Phrase (Arabic), 3. Shifted Adjective Phrase (English) to be Noun Phrase (Arabic), and 4. Shifted Verb Phrase (English) to be Noun Phrase (Arabic),
\end{abstract}

Keyword : shift, Phrase, category, menu, Adobe Photoshop CS5

\section{A. Pendahuluan}

Meskipun bahasa Inggris (BI) dan bahasa Arab (BA) merupakan dua bahasa yang berasal dari rumpun yang berbeda, namun ketika kedua bahasa ini digunakan dalam menu tampilan komputer, struktur dan konstruksi bahasa dirancang dengan efisien dan lebih sederhana, disesuaikan dengan kaidah linguistik untuk memudahkan pengguna komputer dalam memahami fungsi suatu menu.

Suatu menu dalam komputer akan merespon sinyal dari pemakai untuk tindakan yang sama walaupun menggunakan bahasa yang berbeda, misalnya ilustrasi perintah (command) pemakai ke program komputer untuk mencetak suatu file ke media cetak seperti ke dalam kertas, BI menggunakan menu "print", BA menggunakan menu"طباعة" /tiba'ah/.

Istilah print, طباعة /tiba'ah/ dan cetak, keduanya memiliki kategori yang berbeda dalam bahasa masingmasing, kata "print' dapat dikategorikan sebagai verba, dan kata طباعة/tiba'ah/ kategorinya adalah nomina.

Perbedaan kategori kedua contoh diatas, membuktikan adanya pergeseran kata dan berpadan dengan perilaku sintaksis pada bahasa pengguna dengan penyesuaian kaidah tata bahasa, baik Bahasa Inggris maupun Bahasa Arab.

\section{B. Landasan Teori}

\section{Pergeseran}

Penelitian ini membahas tentang pergeseran, karena dianggap lebih logis dari pada penggunaan istilah perbedaan atau perubahan bahasa sumber ke bahasa target, walaupun bidang penelitiannya adalah konstruksi sintaksis, karena hubungan antara bagian-bagian ilmu linguistik sangat berpengaruh dalam penelitian ini.

\footnotetext{
${ }^{1}$ Dosen Yayasan UMN Al Washliyah Medan
} 
Pergeseran bentuk atau transposisi disebut juga dengan shift. "shift" pergeseran bentuk adalah suatu prosedur penerjemahan yang melibatkan pengubahan bentuk gramatikal dari BS ke BT. (Catford, 1965)

Pergeseran tataran adalah proses atau hasil pemindahan suatu satuan dari satu tataran ke tataran lain; mis. Sebuah frase menjadi bagian dari sebuah klausa. (Kridalaksana, 2008:189)

Shift adalah metamessage (subtitution) pendangan, menambah (addition,) penghilangan (deletion) dan penyusunan kembali (recovering) informasi pada teks target. (Zelllermeyer, 1987:76)

Emzir (2015:88) menjelaskan bahwa perubahan linguistik kecil yang terjadi antara TS (Teks Sumber) dan TT (Teks Target) disebut sebagai pergeseran terjemahan (tranlation shift)

\section{Konstruksi Kalimat Menurut Chomsky}

Chomsky (1957) mengemukakan pendapat yang secara teoretis memiliki pandangan tentang konstruksi gramatikal yang berhubungan dengan analisis konstituen, adapun konstruksi tersebut adalah sebagai berikut:

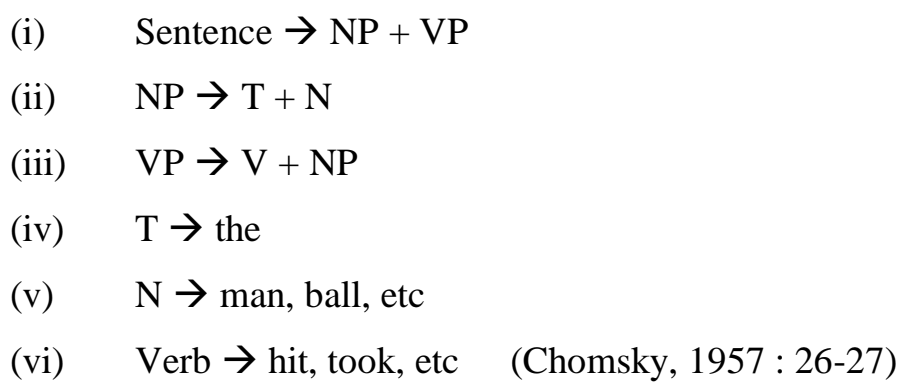

\section{Frasa berdasarkan Konstituen Inti (Head) dan Modifier}

Menurut Crystal (2008:225) :

Head : A term used in the grammatical description of some types of phrase (endocentric phrases) to refer to the central element which is distributionally equivalent to the phrase as a whole; sometimes abbreviated as $\boldsymbol{H}$. Such constructions are sometimes referred to as headed (as opposed to non-headed) or as head phrases (HP) Headedness also determines any relationships of concord or government in other parts of the phrase or sentence. For example, the head of the noun phrase a big man is man.

Burton-Robert (1989:37) mengatakan :

In the phrase containing a modifier, the element that is modified form the essential centre of the phrase and is said to be the HEAD of the phrase.

Selanjutnya Robin (1968:236) mengatakan bahwa :

The word or group sharing the syntactic functions of the whole of a subordinative construction is called head.

Berdasarkan teori - teori di atas dapat disimpulkan bahwa head adalah elemen yang menduduki posisi sentral dan inti dalam konstruksi frasa, sedangkan modifier merupakan elemen attributif yang menerangkan inti dan sentral dari sebuah konstruksi frasa, sebagaimana yang disampaikan Kridalaksana 
(2008:156) bahwa modifier adalah konstituen yang membatasi, memperluas, atau menyifatkan suatu induk dalam frasa.

Sementara itu Al-Khuli (1982:171) mengatakan :

I modifier : wasif, ayyatu kalimatin au tarkibin yasifu kalimatan ukhra sawa`un a kana al mausufu dharfan, am fi'lan, am isman/

Berdasarkan pendapat di atas, terdapat kesesuaian pendapat antara Crystal, Al Khuli bahwa modifier merupakan gramatikal unit dalam konstruksi frasa sebagai atribut dari head, yang menerangkan sentral inti dari sebuah frasa.

\section{Metode Penelitian}

Rancangan yang digunakan dalam penelitian ini adalah rancangan deskriptif, karena penelitian ini bertujuan mendeskripsikan kondisi atau fenomena apa adanya. Kemudian dilakukan pengumpulan data, Data yang ada kemudian diseleksi untuk menghindari tumpukan data, serta dipilah berdasarkan klasifikasi dan kategori pergeseran frasa. Analisis data kualitatif model Miles dan Huberman (1984) terdapat 3 (tiga) tahap: meliputi reduksi data (data reduction), penyajian data (data display) serta Penarikan kesimpulan dan verifikasi (conclusion drawing / verification).

\section{Hasil dan Pembahasan}

Setelah keseluruhan data dianalisis terutama pada menu File, ditemukan hasil bahwa terdapat beberapa Pergeseran (Shift) Kategori Frasa dari Bahasa Inggris ke Bahasa Arab pada program Adobe Photoshop CS5, yaitu :

\section{Pergeseran Frasa Nomina menjadi Frasa Ajektiva}

Pergeseran frasa nomina Bahasa Inggris menjadi frasa ajektiva ke dalam Bahasa Arab dapat dilihat pada konstruksi berikut ini :

a. Pergeseran Konstruksi FN $\Rightarrow \mathrm{N}+\mathrm{FP}$ menjadi FA $\Rightarrow \mathrm{A}+\mathrm{FN}(\mathrm{N}+\mathrm{N}$ definitif $)$

Total of all slices menjadi إبمالي كل الشرائح/ijmaliy kullu al - syaraihil

Frasa nomina total of all slices dan frasa ajektiva إجمالي كل الشرائح /ijmaliy kullu al - syaraihil keduanya dengan urutan regresif, karena nomina total dan ajektiva إجمالى /ijmaliy/ adalah konstituen inti, yang terletak sebelum modifier "of all slices” dan “ "كل الشرائح/kullu al syara ihil.

b. Pergeseran Konstruksi FN $\Rightarrow \mathrm{N}+\mathrm{N}$ menjadi frasa ajektiva terbagi menjadi dua varian yaitu :

1. FA $\Rightarrow$ A definitif + A definitif

Default actions menjadi العمليات الإفتراضية/al-amaliyyat al `iftiradhiyah/

Frasa nomina default action adalah frasa dengan pola progresif, karena konstituen inti actions terletak setelah modifier default, sementara frasa ajektiva العمليات الإفتراضية / amaliyyatu al iftiradhiyah/ 
adalah frasa dengan urutan regresif karena konstituen inti العمليات /al amaliyatu/ terletak sebelum ajektiva definitif الإفتراضية/al iftiradhiyah/.

2. FA $\Rightarrow \mathrm{A}+\mathrm{A}$ definitif

Image statistics menjadi إحصائية الصورة/ihsaiyyatu as-suratil

Frasa nomina image statistic adalah frasa dengan pola progresif, karena konstituen inti statistics terletak setelah modifier image, sementara frasa ajektiva إحصائية الصورة/ihsa iyyatu as-surati/ adalah frasa dengan urutan regresif karena konstituen inti إحصائية /ihsa iyatu/ terletak sebelum modifier الصورة /al suratu/.

c. Pergeseran konstruksi FN $\Rightarrow \mathrm{FN}+\mathrm{N}$ menjadi FA $\Rightarrow \mathrm{A}+\mathrm{FN}(\mathrm{N}+\mathrm{N}$ definitif $)$

Lens correction profile menjadi خاصية تصحيح العدسة/khasiyatu tashihi al adasati/

Frasa nomina lens correction profile adalah frasa dengan pola progresif, karena konstituen inti profile terletak setelah modifier lens correction, sementara frasa ajektiva خاصية تصحيح العدسة/khasiyatu tashihi al adasati/ adalah frasa dengan urutan regresif karena konstituen inti خاصية/khasiyatu/ berupa ajektiva terletak sebelum frasa nomina تصحيح العدسة/ tashihi al adasatil.

d. Pergeseran Konstruksi FN $\Rightarrow \mathrm{A}+\mathrm{N}$ menjadi FA $\Rightarrow \mathrm{A}+\mathrm{A}$

Contoh : white background menjadi خلفية بيضاء/khalfiyatu baidha'/

Frasa nomina white background adalah progresif, karena konstituen inti background terletak setelah modifier white, sementara frasa ajektiva خلفية بيضاء/khalfiyatu baidha'/ adalah regresif karena konstituen inti berupa ajektiva خلفية/khalfiyatu/ yang terletak sebelum modifier berupa ajektiva بيضاء/baidha\%.

\section{Pergeseran Frasa Nomina menjadi Frasa Preposisi}

Pergeseran frasa nomina ke frasa preposisi terdiri dari $2(d u a)$ variasi,yaitu:

a. Pergeseran FN $\Rightarrow$ art.neg. + FN menjadi FP $\Rightarrow$ P+artikel negasi+N + FP

No color management menjadi بلا إدارة للألوان/bila idaratin li al alwan/

b. Pergeseran FN $\Rightarrow$ FN + FP menjadi FP $\Rightarrow$ P + FN

Custom RGB to grayscale menjadi

RGB إلى درجات رمادية مخصص /ila darajatin ramadiyatin mukhassas $R G B /$

\section{Pergeseran Frasa Ajektiva menjadi Frasa Nomina}

a. Pergeseran FA $\Rightarrow$ FA $[$ A $]+$ A menjadi FN $\Rightarrow \mathrm{N}+\mathrm{N}+\mathrm{A}$

relative colorimetric menjadi قياس الألوان النبي /qiyasu al alwani al nisbiy/ 
b. Pergeseran FA $\Rightarrow$ FA $[A]+A$ menjadi FN $\Rightarrow \mathrm{N}+\mathrm{N}+\mathrm{N}$

absolute colorimetric menjadi قياس الألوان المطلق /qiyasu al alwani al mutlaqil

\section{Pergeseran Frasa Verba menjadi Frasa Nomina}

Pergeseran frasa verba BI menjadi frasa nomina ke dalam BA hanya terdapat satu yaitu pergeseran save and close 'simpan dan tutup' menjadi حفظ و إغلاق /hifzun wa iglaqun/'penyimpanan dan penutupan'.

\section{E. Penutup}

Berdasarkan uraian di atas dapat disimpulkan bahwa terdapat 4 jenis pergeseran Kategori Frasa dar bahasa sumber (Inggris) ke bahasa target pada menu Adobe Phoptoshop CS5, yaitu ; 1. Pergeseran (Shift) dari frasa nomina menjadi frasa ajektiva 2. Pergeseran (Shift) dari frasa nomina menjadi frasa preposisi, 3. Pergeseran (Shift) dari frasa ajektiva menjadi frasa nomina 4. Pergeseran (shift) dari frasa verba menjadi frasa nomina.

\section{Daftar Pustaka}

Aiken, Peter dkk. 2002. Microsoft Computer Dictionary fifth edition, New York: Microsoft

Brinton, L.J. 2000. The Structure of Modern English A linguistic introduction. Philadelphia: John Benjamins

Brown, H. Douglas. 2000. Principles of Language Learning and Teaching $4^{\text {th }}$. Edition. New York: The Free Press

Burton-Robert, Noel. 1986. Analysing Sentence : An Introduction to English Syntax. New York: Longman

Carnie, Andrew. 2001. Syntax. Arizona : University of Arizona

Carrol, Joyce Armstrong dkk, 2001. Writing and Grammar Communication in Action Ruby Level. New Jersey: Prentice Hall

Catford, J.C. 1965. A Linguistic Theory of Translation. London: Oxford University Press.

Chomsky, Noam. 1957. Sintactic Structures, With an Introduction by David W. Lightfoot. Berlin: Mouton the Gruyter

Crystal, David. 2008. A Dictionary of Linguistics and Phonetics. Singapore: Blackwell.

Emzir, 2015. Teori dan Pengajaran Penerjemahan, Jakarta : Rajawali

Jurafsky, Daniel \& James H.Martin. 2005. Speech and Language Processing: An introduction to natural language processing, computational linguistics, and speech recognition. t.p.

Kridalaksana, Harimurti. 2008. Kamus Linguistik edisi keempat. Jakarta: Gramedia Utama.

Miles dan Huberman. 1992. Analisis Data Kualitatif. Penerjemah. Tjetjep Rohendi Rohidi. Jakarta : UI Press 
Milles, M.B. dan Huberman, M.A. 1984. Qualitative Data Analysis. London: Sage

Nida. Eugene A. tt. Morphology : the Descriptive Analysis of Words (second edition) Michigan: The University of Michigan Press

Oxford. 2011. Oxford Basic American Dictionary for learners of English. New York: Oxford University

Robin, R.H. 1968. General Linguistics, An Introductory Survey. London: Longmans

Zellemeyer, Michael. 1987. Translation Across Cultures. New Delhi: Bahri 